\title{
Development and validation of contextual measures of sexual harassment perceptions, experiences, and coping for women employees in Ethiopian hospitality workplaces
}

\author{
Mulugeta Dile Worke ${ }^{1,2^{*}} \mathbb{D}$, Zewdie Birhanu Koricha ${ }^{3}$ and Gurmesa Tura Debelew²
}

\begin{abstract}
Background: Sexual harassment among female employees in the hospitality industry is a complex phenomenon, and it has ramifications for employment, psychological, physical, and reproductive health. Nevertheless, our interpretation is constrained by a lack of agreement on its definition and measurement. As a result, hospitality workplaces require accurate tools that provide a detailed understanding of sexual harassment and inputs for action to limit adverse outcomes. Thus, this study aimed to develop a reliable and valid measure of female hospitality employees' perceptions, experiences, and coping features concerning sexual harassment.
\end{abstract}

Methods: Item development, scale development, and scale evaluation were all parts of the design process. Following a round of feedback from the expert group, qualitative results, and a comprehensive literature review on related themes, item pools were created for the first version of the questionnaire. Pre-testing, survey administration, item reduction, and transformation of extracted latent factors of individual items into a unified and measurable construct were also performed. Field testing included five cognitive interviews with women who had experienced sexual harassment, a pre-test study of 30 women, and a survey of 345 women who worked in hospitality workplaces. Finally, tests for dimensionality, reliability, and validity were conducted.

Results: In Bahir Dar, Ethiopia, 345 women working in the hospitality workplaces, with a mean age of $24.31 \pm 4.30$ years, took part in this study. The robust maximum likelihood estimation approach was used to do confirmatory factor analysis. The model's stability was determined by calculating the goodness of fit and the factorial invariance. Subsequently, the validity was confirmed. The findings supported the validity and reliability of the questionnaires designed for the target group. Therefore, the questionnaires can be used as research instruments.

Conclusions: The sexual harassment perceptions, experiences and coping scales provide a locally verified method for assessing sexual harassment in Ethiopia by government authorities and local and international non-governmental organisations, which aid in providing necessary services and the evaluation of efforts aimed at improving workplace safety, workplace health, and psychosocial well-being.

Keywords: Sexual harassment, Reproductive health, Scale development, Coping, Validation, Hospitality industry, Ethiopia

\footnotetext{
*Correspondence: muliedile@gmail.com

${ }^{2}$ Department of Population and Family Health, Faculty of Public Health, Jimma University, Jimma, Ethiopia

Full list of author information is available at the end of the article
}

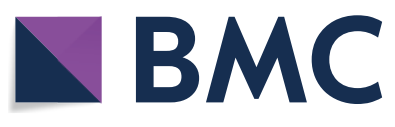

(c) The Author(s) 2022. Open Access This article is licensed under a Creative Commons Attribution 4.0 International License, which permits use, sharing, adaptation, distribution and reproduction in any medium or format, as long as you give appropriate credit to the original author(s) and the source, provide a link to the Creative Commons licence, and indicate if changes were made. The images or other third party material in this article are included in the article's Creative Commons licence, unless indicated otherwise in a credit line to the material. If material is not included in the article's Creative Commons licence and your intended use is not permitted by statutory regulation or exceeds the permitted use, you will need to obtain permission directly from the copyright holder. To view a copy of this licence, visit http://creativecommons.org/licenses/by/4.0/. The Creative Commons Public Domain Dedication waiver (http://creativeco mmons.org/publicdomain/zero/1.0/) applies to the data made available in this article, unless otherwise stated in a credit line to the data. 


\section{Background}

In 2017, the \#MeToo movement revealed that sexual harassment $(\mathrm{SH})$ was prevalent in hospitality settings, such as restaurants and hotels [1]. Since then, several initiatives, policies, and regulations have been proposed to curb SH [2]. Despite these interventions, laws, and legislation created to prevent $\mathrm{SH}$, it persists as one of the most severe issues in the hospitality industry [3-5], a primarily unreported and widespread issue [6]. It is a pertinent and prevailing issue among female employees $[7,8]$, resulting in severe adverse effects [9-12]. In addition to its persistence, prevalence, and under-reporting, it is one of the most detrimental and pervasive barriers to occupation accomplishment and fulfilment [13]. Our qualitative findings $[14,15]$ and other studies have revealed adverse effects on employees' physical, mental, and reproductive health $[16,17]$.

Those subjected to SH were more likely to have had multiple sexual partners and were more likely to have contracted sexually transmitted infections (STIs) in their early adulthood [18]. Hospitality workplaces have been identified as HIV hotspots [19], and HIV prevalence is significant among frontline service employees [20]. It got worse when more young women started selling sex in places like bars, nightclubs, karaoke parlours, and massage parlours [21, 22]. Furthermore, their vulnerability to $\mathrm{SH}$ and its consequences increases because of factors such as tips [23], being less sensitive to unwanted sexual attention, its pervasiveness [24], lack of awareness creation mechanisms [4], precarious employment [25], and little knowledge of hotel managers [5]. As a result of these multidimensional causes and outcomes, there is a need for more rigorous research, particularly in hospitality workplaces.

However, research in this sector is inconclusive and problematic. The lack of expressive prevalence rate is one of the significant encounters [26]. This lack of a meaningful prevalence rate is mainly because of the numerous and disparate definitions of workplace $\mathrm{SH}$ and different methods [26]. The most well-known obstacles include various exposure to $\mathrm{SH}$, single-item measures, and various behavioural assessment scales [26-28]. Moreover, in addition to the infrequent consideration of construct validity, researchers have revealed that such theoretical developments were inadequate $[7,29-31]$.

Nevertheless, different sexual experience questionnaire versions $[4,23,32]$ without additional psychometric evaluation were used [33]. These versions of the sexual experience questionnaire were developed to investigate SH in the military and schools $[34,35]$. The contradiction between the variable description and the use of similar measurement techniques results in significant discrepancies in estimated rates, making it impossible to synthesise or compare SH across studies [36]. Likewise, most questionnaires originate from high-income countries, which tend to be more individualistic and capitalistic [37]. Such scales may be lacking in different sociocultural contexts and may lack ecological validity. Many of the included items were also culturally specific and challenging to adapt to other situations, especially hospitality settings in low-and-middle-income countries [26]. These issues show that $\mathrm{SH}$ is a sophisticated phenomenon that we do not fully comprehend due to a lack of agreement on definition and measurement. Thus, workplaces require reliable tools that provide a comprehensive understanding of $\mathrm{SH}$ and tips for avoiding negative consequences.

In addition, although customers/clients, supervisors, owners, coworkers, and gatekeepers/agents can all be perpetrators [38-41], most studies have been focused on perpetrators who are members of the organisation (supervisors and coworkers) [42] and only a few studies examined customer/guest perpetrators [42-44]. Furthermore, no research has looked into $\mathrm{SH}$ from agents. Even if the severity, coping technique, and impact of harassment change depending on the perpetrator's type, the scale of the problem is cumulative. There have also been no attempts to develop psychometrically sound hospitality industry-specific measures to examine women employee SH perceptions, experiences, and coping strategies.

However, researchers that study SH in the hospitality workplace, such as ourselves, require an accurate, reliable, and valid technique to assess the magnitude and outcomes of $\mathrm{SH}$ among women hospitality workplace employees. Hence, a comprehensive, valid, and reliable tool should be available to measure SH perceptions, experiences, and coping in hospitality workplaces, considering female employees' victimisation by all types of perpetrators.

Thus, this study aimed to develop a reliable and valid technique for measuring $\mathrm{SH}$ perceptions, experiences and coping mechanisms in the hospitality workplace. It would also aid as a platform for other researchers, nongovernmental organisations (NGOs), and government officials to eliminate $\mathrm{SH}$ and its implications for women working in the hospitality industry.

\section{Methods}

The three phases of this study were item development, scale development, and scale evaluation [45]. Furthermore, the nine steps of scale development and validation were followed, including domain(s) identification and item generation, content validity considerations, pre-testing questions, sample and survey administration, item reduction, extraction of latent factors, tests of dimensionality, reliability, and validity $[45,46]$. 


\section{Study setting}

This research was conducted in Bahir Dar, Amhara National Regional State, Northwest Ethiopia, between July 1 and August 30, 2021. The study setting was described in detail elsewhere [47].

\section{Item development}

In this study phase, domains were identified, items were generated, and content validity was considered.

\section{Identification of the domains}

The domain's boundaries and dimensions were defined based on the themes identified in our previous qualitative studies $[15,47]$. Item generation was made more straightforward, and appropriate questions that fit the identified domain dimensions were identified. The identified domains were the sexual harassment perceptions, sexual harassment experiences and coping in hospitality workplaces (SA 1).

\section{Item generation}

The item pool was created inductively (the generation of items from the responses of individuals using the qualitative data obtained through focus group discussions and individual women interviews) and deductively (through the description of the identified domains and the identification of items-through literature review and assessment of existing scales and indicators of the identified domains), using data from prior qualitative studies within this population $[15,47]$ and a thorough examination of published articles on related themes. It was created by evaluating the themes from interviews and focus group discussions with women working in hospitality workplaces in the earlier qualitative findings and a review of related articles published in the literature. The qualitative findings paved the way for creating a practical assessment tool to identify SH-related behaviours among women in hospitality workplaces. Themes from the qualitative data were used to create similar constructs that served as the basis for developing scale items. Then, the item pool's first draft was created. The review of literature gives a theoretical basis for defining the domains. According to DeVellis' [48] recommendations, all statements were written to be straightforward, understandable, and unambiguous to the respondents. We wrote the items positively to minimise the possibility of set responses to questions. The response categories were a Likert scale, with five options (i.e., strongly disagree, disagree, neutral, agree, strongly agree) for $\mathrm{SH}$ perceptions, and (never, once/twice, sometimes, often, and always) for SH experiences and coping with $\mathrm{SH}$. This process formed the first draft of the scales, named women's SH perceptions questionnaire for hospitality workplaces (PSHQ_HW), women's SH experiences questionnaire for hospitality workplaces (SEQ_HW), and women's SH coping mechanisms for hospitality workplaces (SHCQ_HW), with 32, 78 , and 86 items, respectively.

\section{Forward and back-translations}

Two translators worked on the initial version of the questionnaire, written in British English and translated into Amharic (local language). One of the translators was a public health expert, while the other was an Amharic language expert. The translators were fluent in Amharic and had an excellent command of the English language. A third person fluent in Amharic and English looked through the translated version and combined them. Both translators approved the synthesised version.

After that, two different persons back-translated the synthesized version. One was a health practitioner, while the other was not. One of the back-translators held a $\mathrm{PhD}$ in English, while the other was an Ethiopian citizen who had spent many years living and pursuing his $\mathrm{PhD}$ in Australia. The same individual who synthesized the translated versions examined the two back translations. After that, the two back-translated versions were combined into one. The differently back-translated words were noted and debated. The term was inserted into the synthesized version once an agreement was achieved.

\section{Expert consensus}

Finally, a committee of experts compared the original item pool, the translated version, and the back-translated version. Members of the experts' panel chosen for their workplace sexual violence and harassment expertise validated the item pool. The experts were five in number and included one psychologist, one language specialist, two reproductive health specialists, and one professional in health, behaviour, and society. Two of them were $\mathrm{PhD}$ in qualification, and three were masters of science and master of public health. These experts evaluated each item constituting the domain for content relevance, representativeness, and technical quality. They used the clarity of expression, face validity, appropriateness for the construct being measured, and potential for differentiating the target population as a criterion to judge items for retention or deletion [48]. Each expert scored for each item and commented on the modified items. Things that were regularly judged to be omitted were removed. At this stage, we produced the second draft of the items containing 20 PSHQ_HW, 33 SEQ_HW, and 32 SHCQ_HW items. The remaining items were used to create a questionnaire draft, then submitted to two coauthors (GT and ZB) for face and material validation. All experts and the two co-authors provided feedback and 
recommendations about whether such elements should be added, removed, or changed. The inter-rater agreement; content validity index for items; scale-level content validity index, universal agreement calculation; averaging calculation method, and modified kappa were computed to indicate the content validity. Items were maintained after the item evaluation based on the five-member experts' recommendations, and some items were updated to be more readable and explicit (SA 2. A, B \& C).

In addition, three rounds of content expert feedback were obtained using the Delphi Approach. In-depth interviews with our target population were interwoven throughout the three rounds. The questionnaires became more refined as each round progressed. Until there was agreement on the description of the domains, we were researching the potential items we could use.

\section{Cognitive interview}

The complete list of items derived from the expert consensus meeting was tested using cognitive interviewing $[49,50]$ in a sample of women hospitality workplace employees in two rounds to evaluate each item constituting the domain for representativeness of experience from the target population. In the first round, women hospitality workplace employees were recruited consecutively from Bahir Dar city hospitality workplaces. They were asked what they thought each question was asking, whether they could paraphrase each question in their terms, and the logic behind their responses during cognitive interviewing [51] (SA 3). Problems with understanding, the need for clarifications, and any terms or phrases considered inappropriate, insulting, or sensitive were all noted simultaneously. Poorly understood items that were not rephrased and sensitive or unacceptable to respondents were excluded. In the second round, the cognitive interview was conducted to assess the extent to which questions reflect the domain of interest and those answers produce valid measurements. We administered draft questions to 5 interviewees in the second round. We allowed respondents to verbalise the mental process entailed in providing answers. At this stage, we produced the fourth draft of the items containing 17 PSHQ_HW, 29 SEQ_HW, and 27 SHCQ_HW items (SA 4. A \& B).

\section{Scale development}

In this phase, individual items were turned into a harmonious and measuring construct through pre-testing questions, sampling and survey administration, item reduction, and extraction of latent factors.

\section{Pre-testing}

To examine the extent to which the questions reflect the domains being studied and the extent to which answers to the questions produced valid measurements, the last version of the questionnaires was given to a convenience sample of 30 women working in the hospitality industry. First, women's comments on item clarity and items wording were taken. Then, items were checked for readability, explicitly and accurately, reflecting the intended dimensions of behaviours among women hospitality workplace employees.

\section{Sampling}

Lastly, 348 women hospitality workplace employees were taken based on a participant-to-item ratio of 1:10 and a $20 \%$ non-response rate $[52,53]$. Cisgender women were selected systematically from each hospitality workplace in Bahir Dar city, and those older than 18 were included. As it was defined in our previous qualitative study [47], the hospitality workplaces included hotels, bars, fast-food restaurants, restaurants, and cafeterias. Women who have been working in these workplaces were selected randomly using the registers of each hospitality workplaces employee list.

\section{Data collection}

Trained data collectors with experience in data collection on related topics were recruited from Bahir Dar University. The data collectors and supervisors received a two-day intensive training on identifying the women, collecting the data, and overseeing to assure data quality. The data collectors gathered the data using the developed questionnaires at hospitality workplaces in Bahir Dar, our previous qualitative analysis location. The survey was completely voluntary and anonymous. Activities such as intense supervision at the field and daily revision of the collected questionnaire were conducted to ensure the collected data's quality. Since the questionnaire was self-administered in hospitality workplaces, where most female employees cannot read and write a simple sentence, they may face difficulty realising the difference between one item and another. In such conditions, data collectors made their maximum effort to encourage the respondents to ask for any ambiguity in the items and clarify them accordingly. As a result, further clarification was done in any deviation from the tool's correct material (Fig. 1). After the appropriate coding by the principal investigator, the data were entered using the Epi Info version 7 software in a well-prepared data entry template. After the entrance, the data were rechecked its correctness, screened for missing, outlier values and data entry errors using the frequency distribution of the variables and observation of the entered data. Actual and suspected errors were validated against the raw data, and corrections were made. 


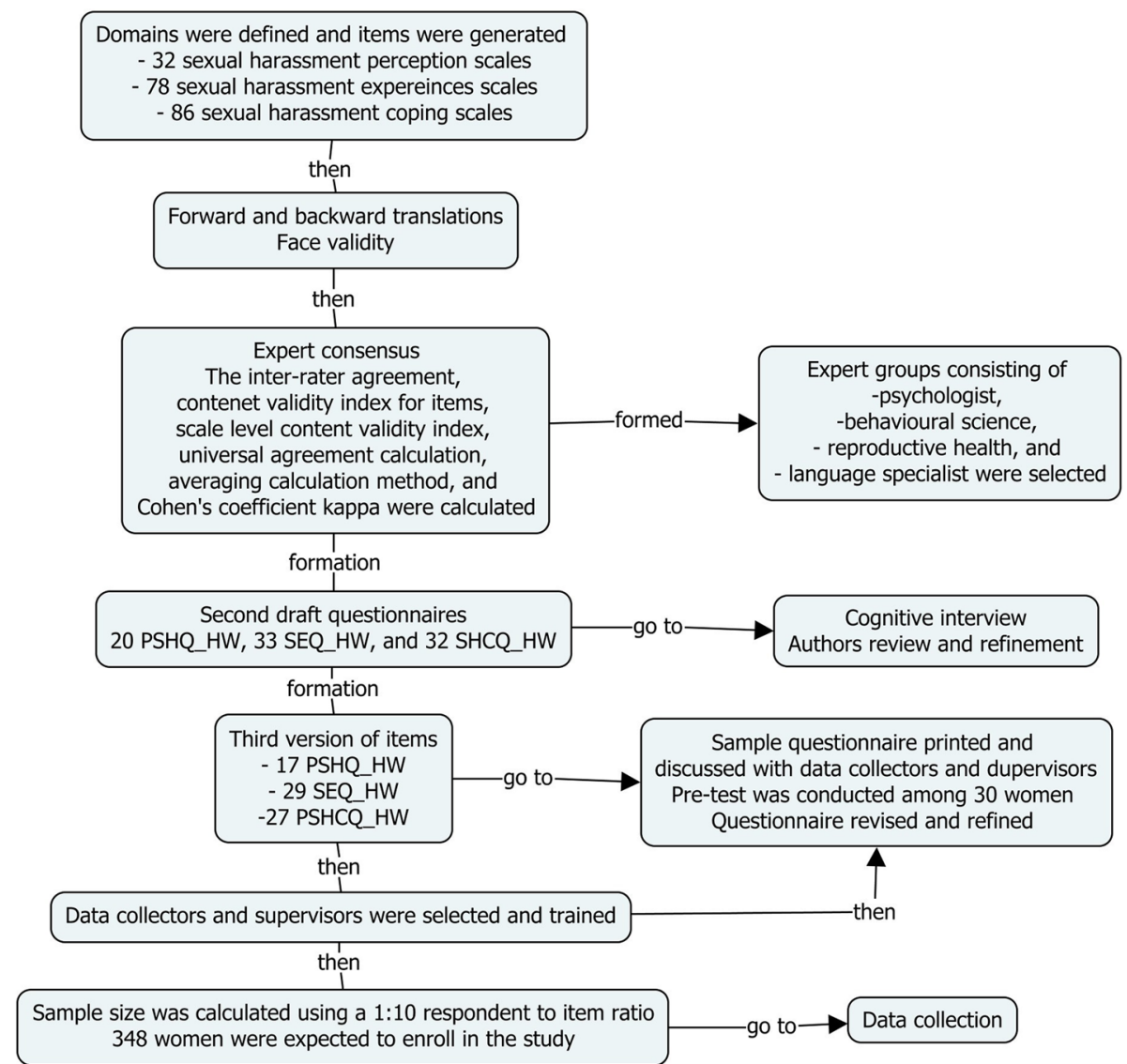

Fig. 1 A flowchart of the sexual harassment perception, experiences and coping mechanisms questionnaires development and validation process in Bahir Dar city hospitality workplaces between July 1 and August 30, 2021

\section{Data analysis}

Statistical Package for the Social Sciences (SPSS, version 24.0 (SPSS, IBM, Armonk, NY, USA)), Analysis of Moment Structure (AMOS, IBM, Armonk, NY, USA), version 23.0), and jamovi version 2.0.0 for windows were used to conduct the statistical analyses. Consequently, the data were analysed for face and content validity, reliability, dimensions, and correlations. In addition, frequency, percentage, mean, and standard deviation were used to examine the distribution of responses to each item. Items with low mean values compared to other items and those supported or rejected by most respondents were examined for adjustment or deletion.

\section{Item reduction analysis}

Item reduction analysis was conducted to ensure only parsimonious, functional, and internally consistent items were included in the analysis. Items with exceptionally low item-scale correlations $(R \geq 0.9)$ [54] were either deleted or merged. Exploratory factor analysis was used to identify potential dimensions under the sub-scales that emerged from the qualitative studies and items that load on each of these dimensions. Items with factor loadings lower than 0.5 and items with cross-loadings $(>0.40)$ were deleted. At least 0.5 variances were explained by the variable to retain in the model.

\section{Extraction of factors}

We used a scree plot and variance explained by the factor model, eigenvalue of $>1$, and the pattern of factor loadings to determine the number of factors retained. Exploratory factor analysis (EFA) was used to determine the optimal number of items that fit a set of items. Kaiser-Meyer-Olkin (KMO) values were used to assess sampling adequacy, and Bartlett's test of sphericity (preferably significant) was used to assess data suitability for factorisation.

The EFA was used to explore the common factors in the latent variable using SPSS version 24.0. The maximum likelihood was used to decide the number of factors to be extracted, and the Promax with Kaiser normalization 
was the rotation method used to identify essential components. The criterion for loading and cross-loading was set at 0.4. As a result, items with loading less than 0.5 and cross-loading greater than 0.4 were removed. This process was repeated until a straightforward structure was achieved where loadings were maximised on putative factors and minimised on the others [55-57]. At least three variables per factor were needed to identify stable factors [58].

\section{Scale evaluation}

At this phase, tests of dimensionality, reliability tests, and validity tests were conducted. The questionnaire's tests of dimensionality were cross-validated using Confirmatory Factor Analysis (CFA). The CFA model's goodness of fit was measured using several model fit indices. The indices which were utilised in this study were the root mean square error of approximation (RMSEA), comparative fit index (CFI), standardised root mean square residual (SRMR), incremental fit index (IFI), CMIN (Chi-square), Comparative Fit Index (CFI), Tucker-Lewis's index (TLI), and PGFI (Parsimony-adjusted Goodness of Fit Index) [59].

Reliability statistics was conducted to assess the internal consistency of the scale, i.e., the degree to which the set of items in the scale co-vary, relative to their sum score. An estimate was conducted using Cronbach's alpha coefficients, composite reliability (CR), and Maximum reliability $(\operatorname{MaxR}(\mathrm{H}))$.

\section{Tests of validity}

\section{Criterion validity}

Predictive validity was conducted to determine if the scores predict future outcomes, and concurrent validity was used to determine the extent to which scale scores have a stronger relationship with criterion measurements made near the time of administration. Bivariate and multivariate regressions were used to estimate the predictive validity, and Pearson product-moment correlation was used for concurrent validity.

\section{Construct validity}

At this phase, convergent validity and discriminant validity were used to determine if the same concept measured in diverse ways yields comparable results and if the concept measured is different from some other concepts. The relationship between scale scores and similar constructs was estimated using Composite Reliability (CR), Average Variance Extracted (AVE), Maximum Shared Variance (MSV), and Average Shared Variance (ASV) [60, 61].

\section{Results}

\section{Sociodemographic characteristics}

Three hundred and forty-five women hospitality employees were participated in this study, making a response rate of $99.13 \%$. Hundred and five (30.4\%) were married at a mean age and standard deviation (SD) of 19.57 $( \pm 3.34)$ years. The mean age and SD of the sample was $24.31( \pm 4.30)$ years. Women employees' average distance and SD travelled $5.56( \pm 9.84)$ kilometres.

The respondents had $1.58( \pm 0.51)$ years of experience, $1498.26( \pm 945)$ Ethiopian birrs monthly salary and 1997.07 ( \pm 1239.40$)$ monthly income, including tips. They were also at work for $10.10( \pm 2.63)$ hours per day (SA 5).

\section{Exploratory factor analysis and scale reduction}

The 17 items of the $\mathrm{SH}$ perceptions scale, 29 items of the $\mathrm{SH}$ experiences scale, and 27 items of $\mathrm{SH}$ coping techniques scale were initially subjected to principal component analysis to determine the optimum number of factors to parsimoniously explain the order and structure of the scale's items. Three factors with an eigenvalue greater than 1.0 [62] were kept in each scale. The maximum likelihood of the factor loading matrix was used to assess solutions for one or three factors. A total of $67.6,58$, and $55.4 \%$ of the variances were explained by the 3-factor solutions for $\mathrm{SH}$ perceptions, experiences, and coping, respectively. The scree plot was investigated further to discover significant factors. Cattell's scree test (i.e., levelling of eigenvalues following an "elbow") confirmed the appropriateness of the three factors solution in each scale. These were also supported by the findings of a parallel analysis [62]. This analysis compared against each eigenvalue to the eigenvalue for the corresponding factor in 1000 randomly generated datasets with similar features to the sample being analysed. The oblique rotation (Promax with the default Kappa 4) was employed to achieve rotated factor loadings because of high correlations between 3 factors $(r \geq 0.5)$ in each scale. Only individual items with primary loadings of 0.4 or higher and no cross-loading of 0.3 and higher were kept for each factor extracted. Cronbach's alpha coefficient was used to determine the scale's internal consistency. Cronbach's Alpha of 0.70 or higher was regarded as satisfactory. Additionally, item-item bivariate correlations were evaluated to ensure that items with exceptionally low $(\mathrm{r}<0.5)$ correlations were deleted.

The extraction of the three factors was supported by EFA, the Kaiser criterion, the resulting scree plot elbow point and parallel analysis of the 17 -item $\mathrm{SH}$ perceptions scale. Three items (i.e., 12, 13, 14) were eliminated using EFA with a Promax rotation for a three-factor solution. 
They all had a loading value of less than 0.4. Three items (i.e., items 9, 10, and 11) loaded the least and caused convergent and discriminant validity issues, so they were removed from the model after further analysis using CFA and convergent and discriminant validity. Finally, an 11-item perceptions scale of $\mathrm{SH}$ was retained (Fig. 2). The EFA, CFA, and discriminant and convergent validity analysis results are presented (Table 1 ).

The identified factors explained $67.6 \%$ of the variance. Bartlett's test of sphericity was significant $\left(\mathrm{X}^{2}=2477.24\right.$, $\mathrm{df}=55, p<0.001)$, and Kaiser-Meyer-Olkin measure was 0.89. Cronbach's Alpha was used to analyse the internal reliability of the final SH perception scale and three subscales. Cronbach's Alpha was $>0.7$ for all subscales, indicating good internal consistency (Table 1). Cronbach's Alpha for the final SH perception scale was 0.91, and deleting more items did not significantly increase Alpha.
Similarly, three factors were extracted by EFA, the Kaiser criterion, the resulting scree plot elbow point and parallel analysis of the 29-item SH experiences scale. Twelve items were eliminated using EFA with the Promax rotation method for a three-factor solution. All eliminated items had a loading value of less than 0.4. Moreover, the three items (i.e., items 19, 20, and 21) loaded the least and caused convergent and discriminant validity issues, so they were removed from the model after further analysis using CFA and convergent and discriminant validity. Finally, a 14-item SH experiences scale was retained. The EFA, CFA, and discriminant and convergent validity analysis results are presented (Table 2).

These identified three factors explained $58 \%$ of the variability. Bartlett's test of sphericity was significant $(\mathrm{x} 2=2528.32, \mathrm{df}=91, p<0.001)$, and the Kaiser-MeyerOlkin measure was 0.90 . Cronbach's Alpha was used to

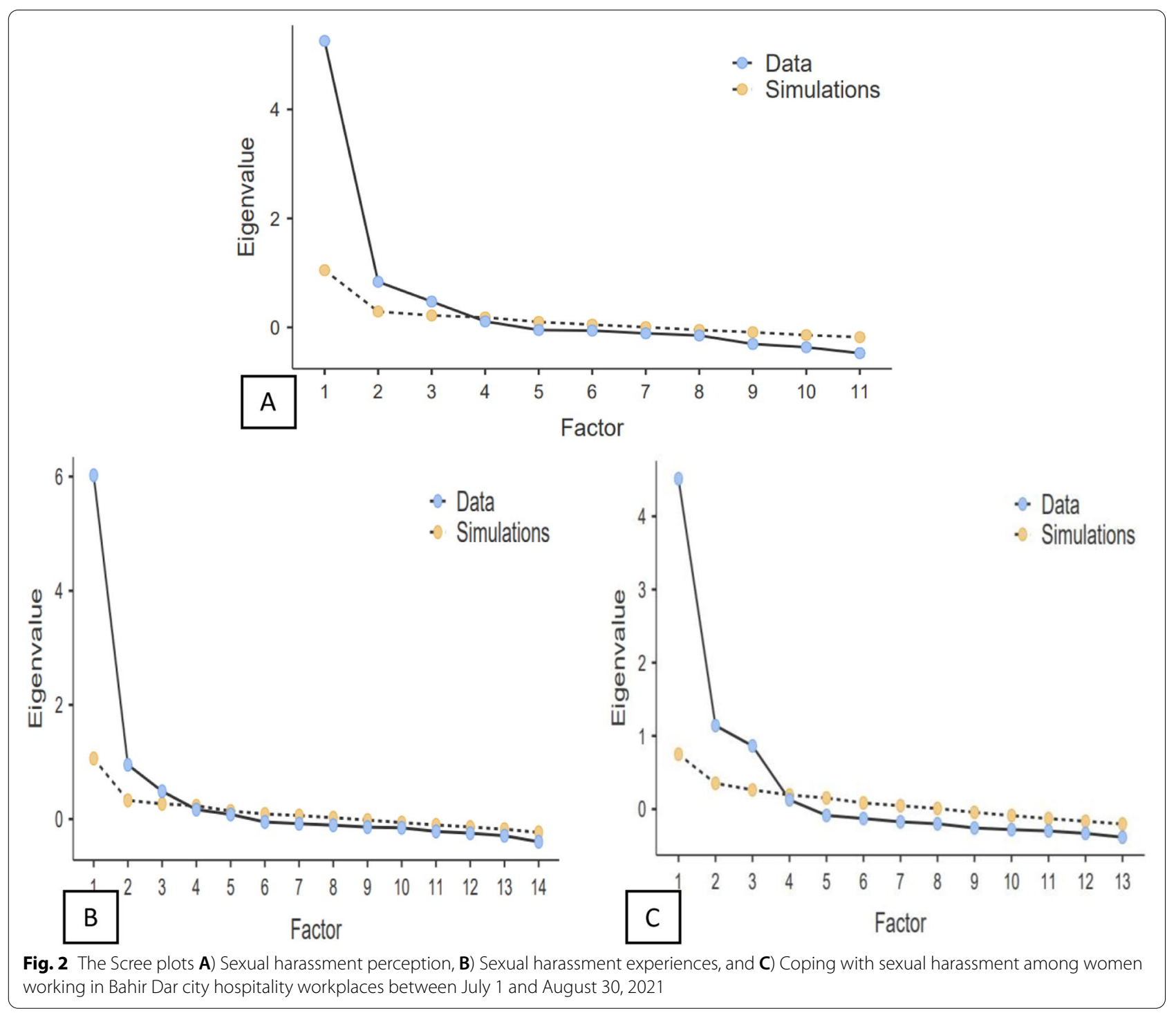


Table 1 Factors, loadings, the Cronbach's Alpha if item deleted, and Cronbach's alpha coefficients of the extracted sexual harassment perceptions questionnaire among women working in Bahir Dar city hospitality workplaces between July 1 and August 30, 2021

\begin{tabular}{|c|c|c|c|c|c|}
\hline \multicolumn{2}{|l|}{ Items } & \multicolumn{3}{|l|}{ Factors } & \multirow{2}{*}{$\begin{array}{l}\text { Cronbach's } \\
\text { Alpha if item } \\
\text { deleted }\end{array}$} \\
\hline Code & Name & Pressuring & Abducting & Touching & \\
\hline PSHQ_HW3 & Sexual harassment is an offer of a new job in exchange for sexual advances & .984 & & & .901 \\
\hline PSHQ_HW2 & $\begin{array}{l}\text { Sexual harassment is preparing women for sexual harassment by providing } \\
\text { better career advancement }\end{array}$ & .897 & & & .900 \\
\hline PSHQ_HW1 & $\begin{array}{l}\text { Sexual harassment is preparing for sexual harassment by making inappropri- } \\
\text { ate promises }\end{array}$ & .724 & & & .905 \\
\hline PSHQ_HW4 & $\begin{array}{l}\text { Sexual harassment is an act of threatening to hurt relatives in exchange for } \\
\text { sexual advances }\end{array}$ & .722 & & & .905 \\
\hline PSHQ_HW5 & $\begin{array}{l}\text { Sexual harassment is threatening to complain or falsely accuse about the } \\
\text { service being provided to the immediate supervisor unless women agree to } \\
\text { sexual favours }\end{array}$ & .534 & & & .904 \\
\hline PSHQ_HW16 & $\begin{array}{l}\text { Sexual harassment is conducting sexual intercourse through force or under } \\
\text { threat of injury against the women will }\end{array}$ & & .956 & & .907 \\
\hline PSHQ_HW17 & $\begin{array}{l}\text { Sexual harassment is slapping, kicking, pinching, or insulting women while } \\
\text { they refuse to agree to a sexual favour }\end{array}$ & & .835 & & .906 \\
\hline PSHQ_HW15 & $\begin{array}{l}\text { Sexual harassment is a forcible take of women for sexual intercourse after } \\
\text { they leave their job }\end{array}$ & & .757 & & .910 \\
\hline PSHQ_HW7 & $\begin{array}{l}\text { Sexual harassment is an act of speaking random sexual jokes to women } \\
\text { while she is at work }\end{array}$ & & & .952 & .907 \\
\hline PSHQ_HW8 & $\begin{array}{l}\text { Sexual harassment is a repeated request of women to engage in sexual } \\
\text { activities }\end{array}$ & & & .735 & .908 \\
\hline PSHQ_HW6 & $\begin{array}{l}\text { Sexual harassment is an act of touching sexual sensitive parts while the } \\
\text { women are at work }\end{array}$ & & & .543 & .902 \\
\hline \multicolumn{2}{|c|}{ Cronbach's alpha coefficient } & .898 & .880 & .834 & .913 \\
\hline
\end{tabular}

analyse the internal reliability of the final $\mathrm{SH}$ perception scale and three subscales. Cronbach's Alpha was $>0.7$ for all subscales, indicating good internal consistency (Table 2). Cronbach's Alpha for the final SH perception scale was 0.91 , and deleting more items did not significantly increase Alpha.

Furthermore, three factors were extracted by EFA, the Kaiser criterion, the resulting scree plot elbow point and parallel analysis of the 27-item SH coping scale. Ten items were eliminated using EFA with the Promax rotation method for a three-factor solution, and three items (i.e., items 14, 16, and 27) were eliminated because of the low loading $(<0.5)$ on each factor dimension of EFA. All eliminated items had a loading value of less than 0.4 . One item (i.e., item 15) loaded the least and caused convergent and discriminant validity issues, so it was removed from the model after further analysis using CFA and convergent and discriminant validity. Finally, 13-item $\mathrm{SH}$ coping scale was retained. The EFA, CFA, and discriminant and convergent validity analysis results are presented (Table 3).

Cronbach's Alpha was used to analyse the internal reliability of the final SH coping scale and three subscales. Three factors were extracted and explained $55.4 \%$ of the variability. Bartlett's test of sphericity was significant $\left(x^{2}=1970.30, \mathrm{df}=78, p<0.001\right)$, and the Kaiser-MeyerOlkin measure was 0.87. Cronbach's Alpha for the entire questionnaire was 0.87 , indicating the reliability of the questionnaire items (Cronbach's alpha coefficient for the three factors was $>0.7$, indicating acceptable reliability) (Table 3). Cronbach's Alpha for the final SH perception scale was 0.91 , and deleting more items did not significantly increase Alpha.

\section{Confirmatory factor analysis}

Structural equation modelling was used to test the measurement models. The goodness of fit, composite reliability, convergent, and discriminant validity were evaluated using IBM SPSS AMOS 23. The measurement models determine the link between the latent variable and the observed measurements and whether the data fit the model well [63]. When fit indices are in the marginal ranges, it is essential to consider the model's consistency as reflected by numerous fit indices [64]. Hence, the current study employs CMIN, SRMR, CFI, TLI, PGFI, and RMSEA to assess the goodness of fit of a given model to the observed data. Thus, the results suggested a good fit for each dimension's factors model based on the indices revealed following CFA. 
Table 2 Factors, loadings, the Cronbach's Alpha if item deleted, and Cronbach's alpha coefficients of the extracted sexual harassment experiences questionnaire among women working in Bahir Dar city hospitality workplaces between July 1 and August 30, 2021

\begin{tabular}{|c|c|c|c|c|c|}
\hline \multicolumn{2}{|l|}{ Items } & \multicolumn{3}{|l|}{ Factor } & \multirow{2}{*}{$\begin{array}{l}\text { Cronbach's } \\
\text { Alpha if item } \\
\text { deleted }\end{array}$} \\
\hline Code & Name & Verbal & Non-verbal & Physical & \\
\hline SEQ_HW10 & How often do perpetrators target you for rumours of sexual promiscuity? & .845 & & & .905 \\
\hline SEQ_HW9 & How often does a perpetrator violate your boundaries? & .814 & & & .903 \\
\hline SEQ_HW8 & $\begin{array}{l}\text { How often does a perpetrator touch you in a way that makes you feel uncomfort- } \\
\text { able? }\end{array}$ & .771 & & & .904 \\
\hline SEQ_HW5 & How often do perpetrators have unwanted sexual conversations with you? & .715 & & & .905 \\
\hline SEQ_HW4 & How often does a perpetrator sexually assault you in public or in private? & 638 & & & .908 \\
\hline SEQ_HW11 & How often do perpetrators insult you by targeting your sexual orientation? & 600 & & & .908 \\
\hline SEQ_HW29 & How often do perpetrators make unwanted attempts to stroke, fondle, or kiss you? & & .851 & & .907 \\
\hline SEQ_HW27 & $\begin{array}{l}\text { How often do perpetrators make unwanted attempts to establish a romantic } \\
\text { sexual relationship with you? }\end{array}$ & & .757 & & .904 \\
\hline SEQ_HW26 & $\begin{array}{l}\text { How often do perpetrators make you afraid that you would be handled by him } \\
\text { poorly if you did not cooperate sexually? }\end{array}$ & & .737 & & .902 \\
\hline SEQ_HW24 & $\begin{array}{l}\text { How often do perpetrators make you feel you were being bribed with some } \\
\text { reward to engage in sexual behaviour? }\end{array}$ & & 688 & & .905 \\
\hline SEQ_HW23 & $\begin{array}{l}\text { How often do perpetrators gaze, leer, or ogle at you in a way that makes you feel } \\
\text { uncomfortable? }\end{array}$ & & 670 & & .905 \\
\hline SEQ_HW17 & How often do perpetrators unnecessarily expose themselves in front of you? & & & 1.072 & .911 \\
\hline SEQ_HW16 & $\begin{array}{l}\text { How often does a perpetrator make sexual assaults, attempts of rape, or actual } \\
\text { rape? }\end{array}$ & & & .474 & .910 \\
\hline SEQ_HW18 & $\begin{array}{l}\text { How often do perpetrators threaten you by filing a complaint about your service } \\
\text { to your supervisor because you refused a sexual request? }\end{array}$ & & & .404 & .906 \\
\hline \multicolumn{2}{|c|}{ Cronbach's alpha coefficient } & .879 & .872 & .769 & .912 \\
\hline
\end{tabular}

Table 3 Factors, loadings, the Cronbach's Alpha if item deleted, and Cronbach's alpha coefficients of the extracted sexual harassment coping questionnaire among women working in Bahir Dar city hospitality workplaces between July 1 and August 30, 2021

\begin{tabular}{|c|c|c|c|c|c|}
\hline \multicolumn{2}{|l|}{ Items } & \multicolumn{3}{|l|}{ Factor } & \multirow{2}{*}{$\begin{array}{l}\text { Cronbach's } \\
\text { Alpha if item } \\
\text { deleted }\end{array}$} \\
\hline Code & Name & Normalisation & Engagement & Help-seeking & \\
\hline SHCQ_HW25 & How often did you keep silent to respond to sexual harassment? & .893 & & & .859 \\
\hline SHCQ_HW24 & How often did you tolerate sexual harassment? & .740 & & & .857 \\
\hline SHCQ_HW23 & How often did you confront the perpetrator? & .696 & & & .860 \\
\hline SHCQ_HW26 & How often did you ignore sexual harassment? & .674 & & & .862 \\
\hline SHCQ_HW22 & How often did you reject the request for sexual harassment? & .590 & & & .866 \\
\hline SHCQ_HW19 & $\begin{array}{l}\text { How often did you consult a psychologist because of the sexual } \\
\text { harassment that you face? }\end{array}$ & & .921 & & .861 \\
\hline SHCQ_HW2O & How often did you negotiate with the perpetrator? & & .773 & & .861 \\
\hline SHCQ_HW18 & $\begin{array}{l}\text { How often did you consult a health care provider because of } \\
\text { sexual harassment? }\end{array}$ & & .765 & & .863 \\
\hline SHCQ_HW21 & How often did you discriminate against the perpetrators? & & .495 & & .865 \\
\hline SHCQ_HW9 & $\begin{array}{l}\text { How often did you get sympathy and understanding from friends } \\
\text { who have had the same problem? }\end{array}$ & & & .739 & .861 \\
\hline SHCQ_HW11 & $\begin{array}{l}\text { How often did you seek reassurance from those who know you } \\
\text { best? }\end{array}$ & & & .736 & .867 \\
\hline SHCQ_HW10 & $\begin{array}{l}\text { How often did you talk to people about the situation because talk- } \\
\text { ing about it makes you feel better? }\end{array}$ & & & 686 & .863 \\
\hline SHCQ_HW8 & $\begin{array}{l}\text { How often did you go to a friend for advice on how to change } \\
\text { sexual harassment? }\end{array}$ & & & .659 & .863 \\
\hline \multicolumn{2}{|c|}{ Cronbach's alpha coefficient } & .846 & .835 & .811 & .871 \\
\hline
\end{tabular}


Confirmatory factor analysis confirmed the presumed theoretical model ideally since standardized regression coefficients between the factors and the individual items were $>0.51$, except ( $p$-value $<0.05$ in all cases) (Fig. 3 ). As shown in the figure, the correlations between factors for perception were $0.53,0.65$ and 0.73 . Similarly, the correlations between factors for $\mathrm{SH}$ experiences were 0.59 , 0.68 , and 0.72 . The correlations between factors for coping with $\mathrm{SH}$ techniques were also $0.44,0.50$, and 0.50 . The $p$-values for all co-variances between factors were $<0.05$.
Finally, the adequacy of models that fit the data is entirely acceptable (Fig. 3) [65].

Three factors were identified from each questionnaire to consider the factor analysis results. For $\mathrm{SH}$ perception, three factors were identified (Table 1). Similarly, for SH experiences, three factors (i.e., Verbal, non-verbal and physical) were identified, and the items were included in each one (Table 2). Furthermore, three factors (i.e., normalisation, engagement, and help-seeking) were identified, and the items were included in each factor (Table 3).

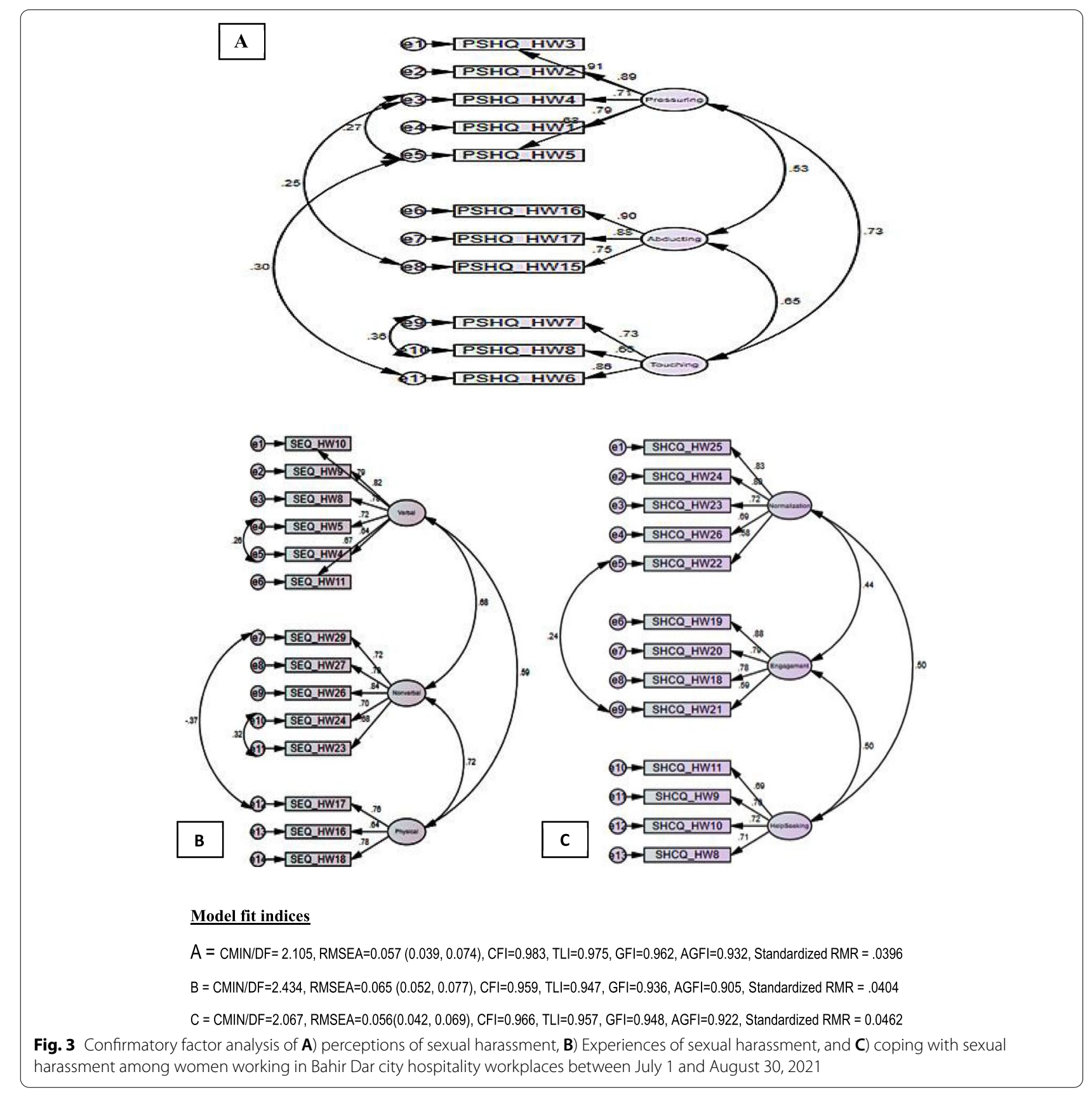




\section{Analysis of reliability and validity}

Reliability analysis was performed on several indicators for each construct to determine their internal consistency [66]. The dependability of the factors was assessed using the Composite Reliability coefficient. The composite reliability calculates a group of latent construct indicators that assess the same construct [67]. Cronbach's Alpha has long been used to assess the consistency of a construct. However, it has recently been discovered that relying solely on the Alpha coefficient to determine reliability may be insufficient [68]. Hence, composite reliability is used, which draws on each item's specified loadings and measurement errors [61]. All composite reliability ratings indicated that the study's measurements were reliable [69].

Concurrent validity was used to determine the extent to which scale scores have a stronger relationship with criterion measurements made near administration using Pearson product-moment correlation. Taking the sample size (n) of 345 , df of 343 , and two-tailed $(95 \% \mathrm{CI})$, the corresponding critical correlation value $\left(r_{c}\right)$ for a significance level of $\alpha=0.05$ for a two-tailed test is $r_{c}=0.106$. Then comparing the composite correlation and each items correlations with the product-moment correlation indicated significance $(P<0.001)$ (SA 6. A, B, and C). For predictive validity, we regressed perceptions, experiences, and coping mechanisms on each subscale. All subscales of perceptions, experiences and coping techniques were significantly associated with their behaviours (SA 7. A \& B).

The declaration of convergent validity was based on reliability $(C R>0.7)$, Average variance extracted $(\mathrm{AVE}>0.5)$, and discriminant validity (MSV $<\mathrm{AVE}$ and square root of AVE greater than inter-construct correlations) $[60,61,70]$. As shown in the table, the composite reliability of all factors was greater than 0.7, which is good. The average variance extracted (AVE) for all constructs was greater than 0.5 , indicating convergent validity. The square roots of all the AVEs were greater than the correlation between the various constructs, all MSVs were less than the AVE, and all square roots of AVE were greater than inter-construct correlations. Therefore, there was discriminant validity (Table 4). Furthermore, all dimensions of $\mathrm{SH}$ perceptions, experiences, and coping techniques had a moderate to high correlation.

\section{Discussion}

This study aimed to develop a culturally appropriate measure of $\mathrm{SH}$ perceptions, experiences and coping techniques in the hospitality workplaces in Ethiopia, which would serve as a platform for other researchers, non-governmental organisations, and government officials involved in eliminating $\mathrm{SH}$ and its implications for women working in the hospitality workplaces. This research is an essential part of evaluating $\mathrm{SH}$ in the hospitality industry and is a helpful instrument for assessing the various dimensions of $\mathrm{SH}$ perceptions, experiences and coping. It thus provided helpful information for developing appropriate reproductive health care management methods in hospitality workplaces. Policies and programs can also be established following enhanced metrics and a greater understanding of the issue's prevalence.

The approach suggested by Boateng et al. [45] for health, social and behavioural research in the development and validation process was used. Content validity was done after item generation and refining, where the meaning for establishing an instrument's validity is debatable [71]. On the other hand, the two-stage approach is widely accepted in the methodological literature and is required for developing new instruments $[72,73]$. The critical point of contention is calculating the agreement indices and the number of experts in determining the

Table 4 Tests of convergent and discriminant validity for sexual harassment perceptions, experiences, and coping techniques among women working in Bahir Dar city hospitality workplaces between July 1 and August 30, 2021

\begin{tabular}{|c|c|c|c|c|c|c|c|}
\hline Perceptions & $\mathrm{CR}$ & AVE & MSV & $\operatorname{MaxR}(\mathrm{H})$ & Abducting & Pressuring & Touching \\
\hline Abducting & 0.883 & 0.716 & 0.425 & 0.901 & 0.846 & & \\
\hline Pressuring & 0.898 & 0.641 & 0.529 & 0.955 & 0.527 & 0.800 & \\
\hline Touching & 0.799 & 0.573 & 0.529 & 0.963 & 0.652 & 0.727 & 0.757 \\
\hline Experiences & $C R$ & AVE & MSV & $\operatorname{MaxR}(\mathrm{H})$ & Nonverbal & Verbal & Physical \\
\hline Nonverbal & 0.866 & 0.565 & 0.518 & 0.877 & 0.752 & & \\
\hline Verbal & 0.877 & 0.546 & 0.468 & 0.937 & 0.684 & 0.739 & \\
\hline Physical & 0.772 & 0.532 & 0.518 & 0.949 & 0.720 & 0.587 & 0.729 \\
\hline Coping & $C R$ & AVE & MSV & $\operatorname{MaxR}(H)$ & Engagement & Normalization & Help Seeking \\
\hline Engagement & 0.847 & 0.585 & 0.246 & 0.876 & 0.765 & & \\
\hline Normalization & 0.848 & 0.531 & 0.253 & 0.931 & 0.439 & 0.729 & \\
\hline Help Seeking & 0.813 & 0.521 & 0.253 & 0.947 & 0.496 & 0.503 & 0.722 \\
\hline
\end{tabular}


risk of inaccuracy. The modified kappa was employed as an index to account for chance agreement, and this index provides data on the degree of agreement that is not determined by chance. Questions about whether alternate methods, such as multi-rater kappa, would produce a correct agreement cannot be answered here.

Moreover, the agreement indices are simply one component in determining content validity and must not be used as the only basis for rejecting or modifying items [74]. The validity of the $\mathrm{SH}$ perceptions, experiences and coping techniques scales was supported in this study by the development process of the instrument and the evaluation of its content validity. Experts' opinions were aided in making decisions regarding the types of issues that existed for specific items. Thus, combined with adjusted kappa and expert-written comments, CVI brought rigour to the content validation of $\mathrm{SH}$ perceptions, experiences, and coping techniques measures. This implies that we used the representation of currently available knowledge in the construct of interest, content validity [28]. Content validity, along with face validity, is the minimum quality criteria. Despite its low place in the validity hierarchy [14, 74 ], content validity is a significant quality indicator of an instrument validity and provides insight into its feasibility and practicability $[72,75,76]$.

In other situations, the written remarks also revealed problems with comprehension, indicating that the intended message was misconstrued. Because of this information, the item was rephrased to be more precise. The importance of the expert's competence cannot be overstated. Various characteristics can be utilised to certify a person's status as an expert, and there are no fixed standards for defining an expert. An expert is characterised as representing a topic of interest in research practice. Knowledge of the assessment technique is fundamental in instrument assessment, and input from stakeholders from other application sectors might be useful [75]. We focused on experiences, perceptions, and coping mechanisms of $\mathrm{SH}$ among women, in hospitality work in the context of hospitality industries and using or developing assessment instruments in the first expert panel of this study. We requested a strong focus on women working in the hospitality industry, as we expected those experts to contribute to developing an instrument that is meaningful, understandable, and practical for women working in the industry. The level to which the narrow focus on hospitality workplaces influenced the relevance of the $\mathrm{SH}$ perceptions, experiences, and coping techniques scales and dimensions could not be determined. Because most experts had additional qualifications, we assume bias is a small risk.

This second modification heavily debated problems acquiring the information needed to answer the questions. Women working in the hospitality industry were frequently reliant on information provided by senior employees or managers if they were there. However, in some situations, these informants were unavailable, and the information needed to answer the questions about SH perceptions, experiences and coping techniques was complex. This is not specific to $\mathrm{SH}$ perceptions, experiences, and coping techniques but a general problem of assessing complex and multifaceted information, creating a professional environment where the observation, collection, communication, reflection, and appraisal of essential information is a prominent part of the hospitality workplace process, overcoming this challenge. Creating a professional environment where the customers are respected is a prominent part of the hospitality industry.

The content was vague. The relevance of the $\mathrm{SH}$ perceptions, experiences and coping techniques information seemed unclear to most respondents. This finding corroborated the notion that $\mathrm{SH}$ perceptions, experiences, and coping mechanisms necessitated a broad understanding. This feedback was required to incorporate the $\mathrm{SH}$ perceptions, experiences and coping techniques in the future. The importance of describing the links between the variable of $\mathrm{SH}$ perspectives, experiences, and coping mechanisms, and their significance to the research of $\mathrm{SH}$ related difficulties, should be emphasised. However, the context in which women encounter $\mathrm{SH}$ impacts their understanding and coping with it. The influence of cognition on the meaning formation of $\mathrm{SH}$ behaviours is powerful. Thus, women employees in the hospitality workplace must adopt more person-centred attitudes towards perpetrators.

Pearson's correlation coefficient created the convergent validity of the $\mathrm{SH}$ perceptions, experiences, and coping technique factors. The correlations were positive, even high in certain situations, indicating similar constructs. The correlations' results proved this validity since they met the criteria provided by Devon et al. [76] for this type of validity. Composite reliability was used to establish the instrument's convergent validity in the second test. Test values of $>0.6$ was considered acceptable [61, 76-78]. Both tests revealed that this form of validity exists. The contrasts between the several elements that made up the scale reflected its discriminant validity. This form of validity emerges when the concepts that make up the system are distinct and related. To establish the validity of these principles, they were evaluated in various methods. The first evaluation involved comparing the AVE's square root to the correlation between the scale's constructs [61]. To ensure discriminant validity, the square root of the AVE should be greater than the correlation between the constructs. 
By looking at the correlations and AVE values, it can be concluded that they have discriminant validity.

There are two different techniques to confirm the validity of this form of validity. Burnkrant and Page [78] have proposed the first. It tries to estimate alternative models so that they all have the same restriction, namely that the correlation between each pair of dimensions must be equal to 1 . On the other hand, each model should be compared using a chi-square test to see if they are statistically different. According to our findings, the differences in the chi-squared values were usually significant. Therefore, the dimensions of $\mathrm{SH}$ perceptions, experiences, and coping techniques were distinct, indicating discriminant validity. The third method is computing the possible correlations between the factors and constructing the confidence intervals for all dimension's correlations. The current study's findings also confirm the presence of this form of validity, as none of the correlations' confidence intervals had the value one at $95 \%$ confidence [79].

The scales for $\mathrm{SH}$ perceptions, experiences and coping techniques can be seen as tools that can help women and supervisors better understand $\mathrm{SH}$. This program provides instructions for traversing a complex web of potential causes and triggers for certain behaviours. In comparison to other questionnaires used in previous surveys in hospitality workplaces, this tool focused on measuring employees' perceptions and coping mechanisms in addition to evaluating experiences. It is essential to note that the SH perceptions, experiences and coping techniques do not provide specific solutions to the problem; instead, they aid in generating a hypothesis (or more) concerning SH perceptions, experiences, and coping.

The estimation and consideration of these scores did not only help select the items for the final survey, but it also allowed prioritizing which opportunities for improvement were most important from the employee's perspective during work and implementation. Based on the employees' experiences, along with perceptions and coping tools, the improvement of the hospitality workplaces women employee's safety may be established within the framework of continuously improving its quality, maximizing the acceptability of the hospitality services by their users, and strengthening the accessibility to services and equity. This knowledge is essential for managers and women employees in this sector. It will provide them with valuable insight into the quality of the provided services and help them proceed to meaningful comparisons amongst their counterparts to identify best practices and priority areas for potential improvement. Therefore, we recommended that these evaluation surveys be used as an ongoing evaluation tool in everyday hospitality workplace SH management practices.
This measurement development and validation process might also help design prevalence studies that use validated measures for $\mathrm{SH}$ in hospitality workplaces of low- and middle-income counties, which will enable us to obtain more precise prevalence estimates across hospitality workplaces to design effective interventions and policies [26]. It might also further update the $\mathrm{SH}$ questionnaires utilised in different settings [80].

\section{Conclusions}

The assessment methods that focus on women working in the hospitality industry are SH perceptions, experiences, and coping techniques. The $\mathrm{SH}$ perceptions, experiences, and coping scales provide a locally verified method to comprehensively assess $\mathrm{SH}$ in Ethiopia by government authorities and local and international non-governmental organisations, which in turn will aid in providing necessary services and the evaluation of efforts to improve workplace safety health psychosocial well-being. The content validity of the $\mathrm{SH}$ perceptions, experiences, and coping technique questionnaires is enhanced by the qualitative study findings, comprehensive literature review, solid theoretical foundation, and the two evaluations representing specific content expertise and practical perspectives. As a result, these help in measuring perceptions, experiences, and coping mechanisms of sexual harassment in low and middleincome countries, which aid in providing necessary services and the evaluation of efforts to improve workplace safety, health, and psychosocial well-being. However, because the $\mathrm{SH}$ perceptions, experiences, and coping technique requires observation, it is recommended to be used as a research tool in Ethiopian hospitality workplaces and other low and middle-income countries. Thus, future studies would ensure that the instrument is checked for improved applicability in diverse work settings.

\footnotetext{
Abbreviations

AMOS: Analysis of Moment Structure; ASV: Average shared variance; AVE: Average variance extracted; CFA: Confirmatory factor Analysis; CFI: Confirmatory Fit Index; CR: composite reliability; EFI: Exploratory Factor Analysis; HIV: Human immunodeficiency Virus; IFI: Incremental Fit Index; IRB: Institutional Review Board; KMO: Kaiser-Meyer-Olkien; $\operatorname{MaxR}(\mathrm{H})$ : Maximum reliability; MPH: Master of Public Health; MSc: Master of Science; MSV: Maximum shared variance; NGOs: Non-governmental Organisations; NY: New York; PhD: Doctor of Philosophy; PSHQ_HW: perception sexual harassment questionnaire for hospitality workplaces; RMSEA: root mean square error of approximation; SA: Supplementary Appendix; SD: Standard deviation; SEQ_HW: sexual harassment experiences questionnaire for hospitality workplaces; $\mathrm{SH}$ : Sexual Harassment; SHCQ_HW: sexual harassment coping mechanisms for hospitality workplaces; SPSS: Statistical Package for social sciences; SRMR: standardised root mean square residual; STIs: Sexually transmitted infections; USA: United States of America.
} 


\section{Supplementary Information}

The online version contains supplementary material available at https://doi. org/10.1186/s13690-022-00828-z.

Additional file 1: SA 1. The identified domains, definitions, and dimensions in developing and validating sexual harassment perception, experiences and coping mechanisms questionnaires for women working in Bahir Dar city hospitality workplaces between July 1 and August 30, 2021. SA 2. The content validity assessments. SA 3. Cognitive Protocol. SA 4. Survey questionnaires. SA 5. Participants' characteristics and working organisation related to Bahir Dar city hospitality workplaces between July 1 and August 30, 2021. SA 6. Pearsons's product-moment correlations for concurrent validity. SA 7. Predictive Validity.

\section{Acknowledgements}

The authors would like to acknowledge the hospitality workplaces, managers and women involved in the research. Debre Tabor University and Jimma University supported this work.

\section{Authors' contributions}

MD participated in the conception and design of the study, carried out the data collection, analyzed and interpreted the data and drafted the manuscript. ZB and GT participated in designing, analysing and interpreting the data and critically revising the manuscript for intellectual content. All authors read, commented on, developed subsequent drafts, and approved the final manuscript.

\section{Funding}

This study was part of the first Author PhD work. Debre Tabor University and Jimma University supplied the remuneration for data collectors and supervisors. On the other hand, the universities played no part in the study design, data collecting, analyses, publication decision, or manuscript preparation.

\section{Availability of data and materials}

The datasets used and/or analysed during the current study are available from the corresponding author on reasonable request.

\section{Declarations}

\section{Ethics approval and consent to participate}

The Jimma University Institutional Review Board, Institute of Health, authorised the study protocol and procedures. The managers of the hospitality workplaces were willing to conduct the study in their organisation. Written info was given to the study participants about the study's purpose and process. They were offered the option of opting out at any point. They were also informed that their characteristics would not be used and that the researchers would keep their information private. Each participant gave their informed consent before data collection. After that, it was entirely up to the participants to participate.

\section{Consent for publication}

Not applicable.

\section{Competing interests}

The authors declare that they have no competing interests.

\section{Author details}

'Department of Midwifery, College of Health Sciences, Debre Tabor University, Debre Tabor, Ethiopia. ${ }^{2}$ Department of Population and Family Health, Faculty of Public Health, Jimma University, Jimma, Ethiopia. ${ }^{3}$ Department of Health, Behavior, and Society, Faculty of Public Health, Jimma University, Jimma, Ethiopia.

Received: 30 August 2021 Accepted: 10 February 2022

Published online: 18 February 2022

\section{References}

1. Ram Y. Metoo and tourism: a systematic review. Curr Issue Tour. 2019:1-19.

2. Islam T, Raihan T, Uddin MA. Sexual harassment at workplace: a systematic review of literature. Business Perspective Review. 2020;2(2):1-14.

3. Madera JM, Guchait P, Dawson M. Managers' reactions to the customer vs coworker sexual harassment. Int J Contemp Hosp Manag. 2018;30(2):1211-27. https://doi.org/10.1108/IJCHM-02-2017-0081.

4. La Lopa JM, Gong Z. Sexual harassment of hospitality interns. J Hospitality Tourism Educ. 2020;32(2):88-101.

5. Nimri R, Kensbock S, Bailey J, Patiar A. Management perceptions of sexual harassment of hotel room attendants. Curr Issue Tour. 2020:113;33:10:3223-55. https://doi.org/10.1080/13683500.2020.1722619.

6. Ram Y, Tribe J, Biran A. Sexual harassment: overlooked and underresearched. Int J Contemp Hosp Manag. 2016;28(10):2110-31. https://doi. org/10.1108/IJCHM-05-2015-0240.

7. Quick JC, McFadyen M. Sexual harassment: have we made any progress? J Occup Health Psychol. 2017;22(3):286.

8. Vincent-Höper S, Adler M, Stein M, Vaupel C, Nienhaus A. Sexually harassing behaviors from patients or clients and care workers' mental health: development and validation of a measure. Int J Environ Res Public Health. 2020;17(7):2570.

9. Fitzgerald LF, Drasgow F, Hulin CL, Gelfand MJ, Magley VJ. Antecedents and consequences of sexual harassment in organizations: a test of an integrated model. J Appl Psychol. 1997;82(4):578-89.

10. Najafi F, Fallahi-Khoshknab M, Ahmadi F, Dalvandi A, Rahgozar M. Antecedents and consequences of workplace violence against nurses: a qualitative study. J Clin Nurs. 2018;27(1-2):e116-28.

11. Kauppinen-Toropainen K, Gruber JE. Antecedents and outcomes of woman-unfriendly experiences: a study of Scandinavian, former soviet, and American women. Psychol Women Q. 1993:17(4):431-56.

12. Wenzhi C, Ling D, Meng L, Min Y. Antecedents of medical workplace violence in South China. J Interpers Violence. 2011;26(2):312-27.

13. MacDermott T. The under-reporting of sexual harassment in Australian workplaces: are organisational processes falling short? Leg Stud. 2020:1-17:40(4):531-47. https://doi.org/10.1017/Ist.2020.24.

14. Worke MD, Koricha ZB, Debelew GT. Perception and experiences of sexual harassment among women working in hospitality workplaces of Bahir Dar city, Northwest Ethiopia: a qualitative study. BMC Public Health. 2021;21(1):1119.

15. Worke MD, Koricha ZB, Debelew GT. Coping strategies and perceived barriers of women hospitality workplace employees to sexual harassment in Bahir Dar city, Ethiopia: a grounded theory approach. BMC Psychology. 2021:9(1):1-14.

16. Willness CR, Steel P, Lee K. A meta-analysis of the antecedents and consequences of workplace sexual harassment. Pers Psychol. 2007:60(1):127-62.

17. Fitzgerald LF, Cortina LM: Sexual harassment in work organizations: A view from the twenty-first century. APA Handbook of the Psychology of Women APA Available at http://www.apa.org/pubs/books/4311534.aspx 2017.

18. Norcott C, Keenan K, Wroblewski K, Hipwell A, Stepp S. The impact of adolescent sexual harassment experiences in predicting sexual risktaking in young women. J Interpers Violence. 2019;0886260519845733.

19. Adal M. Systematic review on HIV situation in Addis Ababa, Ethiopia. BMC Public Health. 2019;19(1):1544.

20. Lakew $Y$, Benedict S, Haile D. Social determinants of HIV infection, hotspot areas and subpopulation groups in Ethiopia: evidence from the National Demographic and Health Survey in 2011. BMJ Open. 2015;5(11): e008669. https://doi.org/10.1136/bmjopen-2015-008669.

21. UNICEF: Examining life experiences and HIV risks of young entertainment workers in four Cambodian cities. In.: New York: Author; 2012.

22. Brody C, Tuot S, Chhea C, Saphonn V, Yi S. Factors associated with sex work among at-risk female youth in Cambodia: a cross-sectional study. AIDS Care. 2016;28(3):339-46.

23. Mensah C. Dependence on tips and sexual harassment vulnerability of hotel employees in Accra, Ghana. J Hospitality Tourism Insights 2019;2(4):451-68. https://doi.org/10.1108/JHTI-02-2019-0018.

24. Alrawadieh Z, Alrawadieh D. Sexual harassment and well-being in tourism workplaces: the perspectives of female tour guides. Tourism 
Gender-Based Violence. 2020;80-92. https://doi.org/10.1079/9781789243 215.0080

25. Reuter M, Wahrendorf M, Di Tecco C, Probst TM, Chirumbolo A, RitzTimme S, Barbaranelli C, lavicoli S, Dragano N. Precarious employment and self-reported experiences of unwanted sexual attention and sexual harassment at work. An analysis of the European Working Conditions Survey. Plos One. 2020;15(5):e0233683.

26. Ranganathan M, Wamoyi J, Pearson I, Stoeckl H. Measurement and prevalence of sexual harassment in low-and middle-income countries: a systematic review and meta-analysis. BMJ Open. 2021;11(6):e047473. https://doi.org/10.1136/bmjopen-2020-047473.

27. Barling J, Rogers AG, Kelloway EK. Behind closed doors: in-home workers' experience of sexual harassment and workplace violence. J Occup Health Psychol. 2001;6(3):255-69.

28. Cortina LM, Areguin MA. Putting people down and pushing them out: sexual harassment in the workplace. Annu Rev Organ Psych Organ Behav. 2021;8:285-309.

29. Fitzgerald LF, Gelfand MJ, Drasgow F. Measuring sexual harassment: theoretical and psychometric advances. Basic Appl Soc Psychol. 1995:17(4):425-45.

30. Nielsen MBD, Kjær S, Aldrich PT, Madsen IE, Friborg MK, Rugulies R, et al. Sexual harassment in care work-dilemmas and consequences: a qualitative investigation. Int J Nurs Stud. 2017;70:122-30.

31. Lengnick-Hall ML. Sexual harassment research: a methodological critique. Pers Psychol. 1995;48(4):841-64

32. Mensah C. Job-client gender context and sexual harassment vulnerability within the hotel sector. Int J Hosp Tour Adm. 2019:1-26:2-87. https://doi. org/10.1080/15256480.2019.1692756.

33. Burn SM. The psychology of sexual harassment. Teach Psychol. 2019;46(1):96-103.

34. Fitzgerald LF, Magley VJ, Drasgow F, Waldo CR. Measuring sexual harassment in the military: the sexual experiences questionnaire (SEQ-DoD). Mil Psychol. 1999;11(3):243-63.

35. Schell TL, Cefalu M, Morral AR: Development of a Short Form Measure of Sexual Harassment Risk in the Military. In.: RAND Corporation Santa Monica United States; 2019

36. Morral AR, Gore KL, Jaycox L, Schell T, Farris C, Kilpatrick D, Street A, Tanielian T: Sexual assault and sexual harassment in the US military: Top-line estimates for active-duty coast guard members from the 2014 RAND military workplace study. In.: RAND NATIONAL DEFENSE RESEARCH INST SANTA MONICA CA; 2014.

37. McDonald P. Workplace sexual harassment 30 years on: a review of the literature. Int J Manag Rev. 2012;14(1):1-17.

38. Mkono M. Zimbabwean hospitality students' experiences of sexual harassment in the hotel industry. Int J Hosp Manag. 2010;29(4):729-35.

39. Teng C-C, Hsu S-M, Lai H-S, Chen H. Exploring ethical incidents in the Taiwanese hotel industry. Int J Hosp Tour Adm. 2018;1-18:422-39. https:// doi.org/10.1080/15256480.2018.1511496.

40. Waudby B, Poulston J. Sexualisation and harassment in hospitality workplaces: who is responsible? International journal of culture. Tour Hosp Res. 2017:11(4):483-99.

41. Ram Y. Hostility or hospitality? A review on violence, bullying and sexual harassment in the tourism and hospitality industry. Curr Issue Tour. 2018;21(7):760-74.

42. Gettman HJ, Gelfand MJ. When the customer should not be king: antecedents and consequences of sexual harassment by clients and customers. J Appl Psychol. 2007;92(3):757.

43. Morganson VJ. The line in the sand: understanding customer sexual harassment through a psychological contract framework; 2008

44. Morganson VJ, Major DA. Exploring retaliation as a coping strategy in response to customer sexual harassment. Sex Roles. 2014:71(1-2):83-94.

45. Boateng GO, Neilands TB, Frongillo EA, Melgar-Quiñonez HR, Young SL. Best practices for developing and validating scales for health, social, and behavioural research: a primer. Front Public Health. 2018;6:149.

46. Carpenter S. Ten steps in scale development and reporting: a guide for researchers. Commun Methods Meas. 2018;12(1):25-44.

47. Worke MD, Koricha ZB, Debelew GT. Perception and experiences of sexual harassment among women working in hospitality workplaces of Bahir Dar city, Northwest Ethiopia: a qualitative study. BMC Public Health. 2021:21(1):1-18.
48. Ashton KR: The public image of psychologists: development and validation of an attitudes toward psychologists scale. The Ohio State University; 2001

49. Mehrotra S. Cognitive interviewing: an overview and an illustration. J Indian Acad Appl Psychol. 2007;33(1):81-4.

50. Habtamu K, Alem A, Medhin G, Fekadu A, Prince M, Hanlon C. Development and validation of a contextual measure of functioning for people living with severe mental disorders in rural Africa. BMC Psychiatry. 2016:16(1):311.

51. Prince M. Measurement validity in cross-cultural comparative research. Epidemiol Psychiatr Sci. 2008;17(3):211-20.

52. Watson $R$, Thompson DR. Use of factor analysis in journal of advanced nursing: a literature review. J Adv Nurs. 2006;55(3):330-41.

53. Nunnally JC: Psychometric Theory 2nd ed. In.: Mcgraw hill book company; 1978.

54. Hawker G, Davis A, French M, Cibere J, Jordan J, March L, et al. Development and preliminary psychometric testing of a new OA pain measurean OARSI/OMERACT initiative. Osteoarthr Cartil. 2008:16(4):409-14.

55. Field A. Discovering statistics using IBM SPSS statistics: sage; 2013.

56. Gaskin CJ, Happell B. On exploratory factor analysis: a review of recent evidence, an assessment of current practice, and recommendations for future use. Int J Nurs Stud. 2014;51(3):511-21.

57. Costello AB, Osborne J: Best practices in exploratory factor analysis: Four recommendations for getting the most from your analysis. Practical assessment, research, and evaluation 2005, 10(1):7.

58. Comrey AL. Factor-analytic methods of scale development in personality and clinical psychology. J Consult Clin Psychol. 1988;56(5):754.

59. Hu L-t. Bentler PM: fit indices in co-variance structure modelling: sensitivity to under parameterized model misspecification. Psychol Methods. 1998;3(4):424.

60. Gaskin J, Lim J: Master validity tool. AMOS Plugin In: Gaskination's StatWiki 2016.

61. Fornell C, Larcker DF. Evaluating structural equation models with unobservable variables and measurement error. J Market Res. 1981;18(1):39-50

62. Horn JL. A rationale and test for the number of factors in factor analysis. Psychometrika. 1965;30(2):179-85.

63. Henseler J, Ringle CM, Sinkovics RR: The use of partial least squares path modelling in international marketing. In: New challenges to international marketing. edn.: Emerald Group Publishing Limited; 2009.

64. Brown TA. Confirmatory factor analysis for applied research: Guilford publications: 2015

65. Hu L, Bentler PM. Cutoff criteria for fit indexes in co-variance structure analysis: conventional criteria versus new alternatives. Struct Equ Model Multidiscip J. 1999;6(1):1-55.

66. Lu C-S, Lin C-C, Tu C-J. Corporate social responsibility and organisational performance in container shipping. Int J Log Res Appl. 2009:12(2):119-32.

67. McQuitty $S$. The purposes of multivariate data analysis methods: an applied commentary. J Afr Bus. 2018;19(1):124-42.

68. Cronbach LJ, Shavelson RJ. My current thoughts on coefficient alpha and successor procedures. Educ Psychol Meas. 2004;64(3):391-418.

69. Hair JF, Sarstedt M, Ringle CM, Mena JA. An assessment of the use of partial least squares structural equation modelling in marketing research. J Acad Market Sci. 2012;40(3):414-33.

70. Aila F, Ombok B. Validating measures in business research: practical implications; 2015

71. Beckstead JW. Content validity is naught. Int J Nurs Stud. 2009:46(9):1274-83.

72. Polit $D F, B e c k C T$. The content validity index: are you sure you know what is being reported? Critique and recommendations. Res Nurs Health. 2006;29(5):489-97.

73. Haynes SN, Richard D, Kubany ES. Content validity in psychological assessment: a functional approach to concepts and methods. Psychol Assess. 1995:7(3):238.

74. Halek M, Holle D, Bartholomeyczik S. Development and evaluation of the content validity, practicability, and feasibility of the innovative dementiaoriented assessment system for challenging behaviour in residents with dementia. BMC Health Serv Res. 2017;17(1):1-26.

75. Rubio DM, Berg-Weger M, Tebb SS, Lee ES, Rauch S. Objectifying content validity: conducting a content validity study in social work research. Soc Work Res. 2003:27(2):94-104. 
76. DeVon HA, Block ME, Moyle-Wright P, Ernst DM, Hayden SJ, Lazzara DJ, et al. A psychometric toolbox for testing validity and reliability. J Nurs Scholarsh. 2007;39(2):155-64.

77. Bagozzi RP, Yi Y. On the evaluation of structural equation models. J Acad Market Sci. 1988;16(1):74-94.

78. Burnkrant RE, Page TJ Jr. An examination of the convergent, discriminant, and predictive validity of Fishbein's behavioural intention model. J Market Res. 1982;19(4):550-61.

79. Anderson JC, Gerbing DW. Structural equation modelling in practice: a review and recommended two-step approach. Psychol Bull. 1988;103(3):411.

80. Gutek BA, Murphy RO, Douma B. A review and critique of the sexual experiences questionnaire (SEQ). Law Hum Behav. 2004;28(4):457-82.

\section{Publisher's Note}

Springer Nature remains neutral with regard to jurisdictional claims in published maps and institutional affiliations.

- fast, convenient online submission

- thorough peer review by experienced researchers in your field

- rapid publication on acceptance

- support for research data, including large and complex data types

- gold Open Access which fosters wider collaboration and increased citations

- maximum visibility for your research: over $100 \mathrm{M}$ website views per year

At BMC, research is always in progress.

Learn more biomedcentral.com/submissions 